counterfactual mindset, etc.) that have been examined in earlier research. Future research may explore further the unexpected impact of mundane daily tasks on well-being. For example, choosing the tastiest dish from a long menu in a restaurant, watching American $I d o l$, and grading students' assignments may all involve temporary activation of the maximizing mindset, which may in turn amplify regrets and dissatisfaction in unrelated life domains.

For more information contact: jingjing-ma@kellogg.northwestern.edu

\title{
The Tyranny of Utilitarian but Democracy of Hedonic Choices
}

\author{
Eugene Chan, University of Toronto, Canada* \\ Andrew Mitchell, University of Toronto, Canada
}

In 2009, Coca-Cola launched its Freestyle soda machines in cities across the United States. The machines allow consumers to dispense their own soda from 125 choices, with regular and diet versions of Coke, Barq's, and Powerade, among other brands, and soda flavours as unique as guava, orange, and peach. Today, there are over 66,000 "fans" on Facebook, with many commenting that the machines are "the greatest thing ever" and one fan being "heartbroken" that a local Burger King in South Carolina did not have one. This success story seems to go against the argument that offering choices can be detrimental to consumer satisfaction. Indeed, making a choice - even a simple one - is effortful for consumers (Baumeister et al., 1998; Festinger, 1962; Luce et al., 1999; Tversky \& Shafir, 1992). Increasing the number of options thus only makes the decision more difficult for consumers. This phenomenon is known as “choice overload” (Fasolo, McClelland, \& Todd, 2007; Gourville \& Soman, 2005; Iyengar \& Lepper, 2000; Schwartz, 2000), among other labels.

In this research, we hypothesize that offering utilitarian choices decreases, but offering hedonic ones increases, consumer satisfaction. Utilitarian choices fulfil instrumental needs, while hedonic choices fulfil experiential desires. Goals research indicates that consumers are driven by goals that they value (Carver \& Scheier, 1998). Although hedonic choices fulfil a goal like utilitarian choices, the goal here is in what it symbolizes. Consumers signal their own identity by choosing what products to buy, what attitudes they profess, and what preferences they hold (Levy, 1959; Wernerfelt, 1990). Thus, as hedonic goals are personally-driven, autonomous, and valued, consumers expend more effort to make and be more motivated by hedonic than utilitarian choices. Within the context of offering choices, consumers should thus perceive any interference to making hedonic choices as a restriction on their autonomy and on themselves as human beings, thereby prompting even greater effort towards such goal pursuits. Thus, the difficulty that arises from offering any type of choice should deplete consumers making utilitarian choices, but it should motivate those making hedonic ones. In Experiment 1, participants' task was to choose a birthday card, either for a co-worker (utilitarian) or for a close friend (hedonic). They chose a card from a selection of either 6 or 15 options. Participants making a utilitarian (hedonic) choice were less (more) satisfied from choosing among 15 than among 6 cards. Further analysis revealed that more options increased perceived difficulty regardless of choice type, replicating previous findings regarding choice overload. However, on measures of perceived autonomy, participants making a utilitarian (hedonic) choice perceived less (more) autonomy from choosing among 15 than among 6 cards, Mediation analyses indicate that perceived difficulty lowered satisfaction from utilitarian choices, but perceived autonomy increased it from hedonic ones. Taken together, the results suggest that offering more hedonic choices increases perceived autonomy from choosing, thereby increasing satisfaction.

Experiment 2 tested the hypothesis that making utilitarian choices depletes, while making hedonic choices motivates, consumers. This is because choosing is difficulty and draws upon the same executive mental resources as with most acts (Baumeister et al., 1998; Bruyneel et al., 2006; Vohs et al., 2008; Wang et al., 2010). In this experiment, participants chose a coffee either to stay awake (utilitarian) or to relax (hedonic). They then chose a coffee from either 5 or 18 options. Afterwards, participants completed the three questions on the Cognitive Reflection Test (Frederick, 2005). Results regarding satisfaction from choice paralleled Experiment 1. 
Participants making a utilitarian (hedonic) choice were less (more) satisfied from choosing among 18 than among 5 coffees. On the CRT, participants making a utilitarian (hedonic) choice scored lower (higher) after choosing from among 18 than 5 coffees. These findings suggest that making difficulty utilitarian choices depletes consumers, but making difficult hedonic choices motivates them. This follows from the idea that autonomous choices vitalize consumers in both the consumer and social psychology domains (Choi \& Fishbach, 2011; Laran \& Janiszewski, 2011; Nix et al., 1999; Ryan \& Deci, 2008).

Across these two experiments, we find that offering utilitarian choices decreases, while offering hedonic ones increases, consumer satisfaction. This is because utilitarian choices fulfil externally-driven goals, while hedonic choices fulfil personally-driven ones that are more valued and motivating than others. While increasing the number of options makes it more difficult to choose, this difficulty depletes consumers making utilitarian choices, but it motivates those making hedonic ones. With more hedonic choices, consumers become aware of what makes them happy, making them better informed about the decision and themselves (Diener $\&$ Biswas-Diener, 2002; Eaton \& Lipsey, 1979). Hedonic choices can also offer variety to meet consumers' need for stimulation and to prevent satiation (Redden, 2008; Simonson, 1990). And as consumers pursue what makes them happy, those who are satisfied with their hedonic choices should repeat their purchases and drive in-store traffic (Broniarczyk et al. 1998; Hoch et al. 1999; Kahn and Wansink 2004).

To Schwartz (2000), there is the "tyranny" of choice. But the question is not whether consumers have choices - but rather, it is what type of choice that they are making. His argument that offering choices undermines self-determination only applies to consumers making utilitarian choices. But when consumers make personally-valued, autonomous, hedonic choices, there is what we call the “democracy" of choice. Consumers strive for volition by expressing their tastes, desires, and fantasies (deCharms, 1968; Deci et al., 1994; Moller et al., 2006), such that offering hedonic choices assists in this regard. With no choice at all to express their individuality and themselves, consumers can not perceive themselves as autonomous agents - and as a result, they cease to become human beings.

For more information contact: euges.chan@mail.utoronto.ca

\subsection{Individual Papers: When the Going Gets Tough: Coping with Negative Consumption Situations}

\section{Room: El Capistrano}

Chair: Elise Chandon Ince, Virginia Tech

\section{Construal and Coping: How I Cope Affects How I Think}

DaHee Han, Indiana University, USA*

Adam Duhachek, Indiana University, USA

Consumers engage in a variety of coping strategies when confronted with stressful situations. Some consumers may engage in problem-focused coping strategies (i.e., efforts to change the cause of stress; Lazarus and Folkman 1984) while others may tend to employ emotion-focused coping strategies (i.e., efforts to regulate one's emotional responses to the sources of stress; Lazarus and Folkman 1984). Although previous findings in the coping literature enhance our understanding of the factors that influence when consumers employ either approach, little research investigates how the use of specific coping strategies may influence subsequent information processing. This research proposes unique consequences resulting from reliance on either problem-focused or emotionfocused coping by conjoining coping theory with Construal Level Theory (Trope and Liberman 2003, 2010).

We propose that the use of specific coping strategies is associated with systematic variations in construal levels. In particular, we posit that consumers who employ problem-focused coping will adopt lower level construals because they mentally represent their coping in 